\title{
Pathological Mechanisms and Clinical Aspects of GBA1 Mutation-Associated Parkinson's Disease
}

Thomas Benjamin Stoker ${ }^{1,2,3}$ • Kelli Majella Torsney ${ }^{4,5} \bullet$ Roger A. Barker ${ }^{1,2,3}$

${ }^{1}$ John van Geest Centre for Brain Repair, Department of Clinical Neurosciences, University of Cambridge, Forvie Site, Cambridge, CB2 OPY, UK; ${ }^{2}$ Wellcome Trust-Medical Research Council Stem Cell Institute, University of Cambridge, UK; ${ }^{3}$ Department of Neurology, Cambridge University Hospitals NHS Foundation Trust; UK; ${ }^{4}$ Department of Medicine for the Elderly, Cambridge University Hospitals NHS Foundation Trust, UK; ${ }^{5}$ Clinical Gerontology Unit, Department of Public Health and Primary Care, University of Cambridge, UK

Author for Correspondence: Thomas Stoker, John van Geest Centre for Brain Repair, Department of Clinical Neurosciences, University of Cambridge, Forvie Site, Cambridge, CB2 OPY, UK. E-mail: tbs26@cam.ac.uk

Doi: http://dx.doi.org/10.15586/codonpublications.parkinsonsdisease.2018.ch3

Abstract: Parkinson's disease (PD) is a common neurodegenerative disorder, characterized by a motor syndrome consisting of bradykinesia, rigidity, resting tremor, and postural instability. Mutation in the GBAl gene, which encodes the lysosomal enzyme glucocerebrosidase, has recently emerged as the most common genetic abnormality associated with PD. Approximately 5\% of PD patients carry a GBA1 mutation, in comparison to $<1 \%$ of the healthy population.

In: Parkinson's Disease: Pathogenesis and Clinical Aspects. Stoker TB, Greenland JC (Editors). Codon Publications, Brisbane, Australia. ISBN: 978-0-9944381-6-4; Doi: http://dx.doi. org/10.15586/codonpublications.parkinsonsdisease.2018

Copyright: The Authors.

Licence: This open access article is licenced under Creative Commons Attribution 4.0 International (CC BY 4.0). https://creativecommons.org/licenses/by-nc/4.0/ 
Heterozygous or homozygous GBA1 mutations increase the risk of PD 20-30 fold. The pathogenic mechanisms of GBA1 mutation-associated PD are not fully understood. Several studies suggest loss of enzyme activity underlies the pathogenicity of GBA1 mutations, while others suggest that a gain of function due to enzyme misfolding is important. Lysosomal-autophagic and mitochondrial dysfunction, as well as endoplasmic reticulum stress and alpha-synuclein accumulation, have all been demonstrated in association with GBA1 mutation. The clinical features of GBA1 mutation-associated PD are similar to that of sporadic disease but with an earlier age of onset and a more rapid cognitive and motor decline. Given this impact of clinical course and its relatively high frequency, understanding the pathogenic mechanisms of GBA1 mutations will allow for the development of targeted, potentially disease-modifying treatments that will have implications for many patients with PD.

Keywords: $\alpha$-synuclein; Gaucher disease; GBA1; Glucocerebrosidase; Parkinson's disease

\section{INTRODUCTION}

Parkinson's disease (PD) is a common neurodegenerative disorder, characterized clinically by a typical motor syndrome consisting of bradykinesia, rigidity, resting tremor, and postural instability (1). The motor disorder in part results from the loss of striatal dopamine, as a consequence of degeneration of the dopaminergic neurons of the substantia nigra (1). Most individuals also develop neuropsychiatric manifestations (such as anxiety, depression, and hallucinations), sleep disturbances, autonomic dysfunction, and cognitive decline and dementia, due to involvement of extra-nigral brain regions including the cortex and multiple brainstem sites (2).

The natural history of PD may follow a more benign motor-predominant course in some patients, while in others the disabling non-motor features predominate. The underlying basis of the clinical heterogeneity is poorly understood, but it is becoming clear that this is, at least in part, due to genetic factors $(1,3,4)$. One of these genetic risk factors is mutation in the GBA1 gene, which has emerged numerically as the most important genetic abnormality associated with PD $(5,6)$, being found in about $5 \%$ of patients with the so-called sporadic PD. In this chapter, we discuss the epidemiology, pathogenic mechanisms, clinical features, and implications for treatment of GBA1 mutation-associated PD.

\section{THE GBA1 GENE AND GLUCOCEREBROSIDASE}

GBA1 encodes the lysosomal enzyme glucocerebrosidase (GCase). The gene consists of a 7.6-kb sequence, with 11 exons and 10 introns, and is sited on the long arm of chromosome 1 (7). GBA1 gives rise to at least two mRNA sequences, resulting from alternate polyadenylation sites, and the resultant amino acid peptides are processed to form the 496 amino acid mature protein (6); $16 \mathrm{~kb}$ downstream of 
the GBA1 gene lies a 5.7-kb sequence, which is almost identical to the GBA1 gene $(6,7)$. This pseudogene has complicated genetic sequencing and the identification of novel pathogenic mutations.

GCase is responsible for the hydrolysis of glucosylceramide (also termed glucocerebroside) glycosphingolipids to ceramide and glucose, in the lysosome (8). It consists of three domains, with the catalytic site residing in the third domain, which has the structure of a triose phosphate isomerase barrel (9). The enzyme is synthesized in the rough endoplasmic reticulum (ER) and traverses the Golgi apparatus via a phosphatidylinositol-4-kinase (PI4K)-dependent pathway to the lysosome. Transit is mediated by a specific transporter, lysosomal membrane protein-2 (LIMP-2) $(10,11)$. This differs from the majority of other lysosomal proteins, where delivery to the lysosome is dependent on mannose6-phosphate receptors (12). GCase and LIMP-2 are bound in the ER, and they pass through the Golgi apparatus in complex. On delivery to the lysosome, the low pH results in the dissociation of LIMP-2 from GCase (Figure 1) (11). Enzyme activity is dependent on the substrate-presenting co-factor saposin $C$, which is cleaved from prosaposin (13).

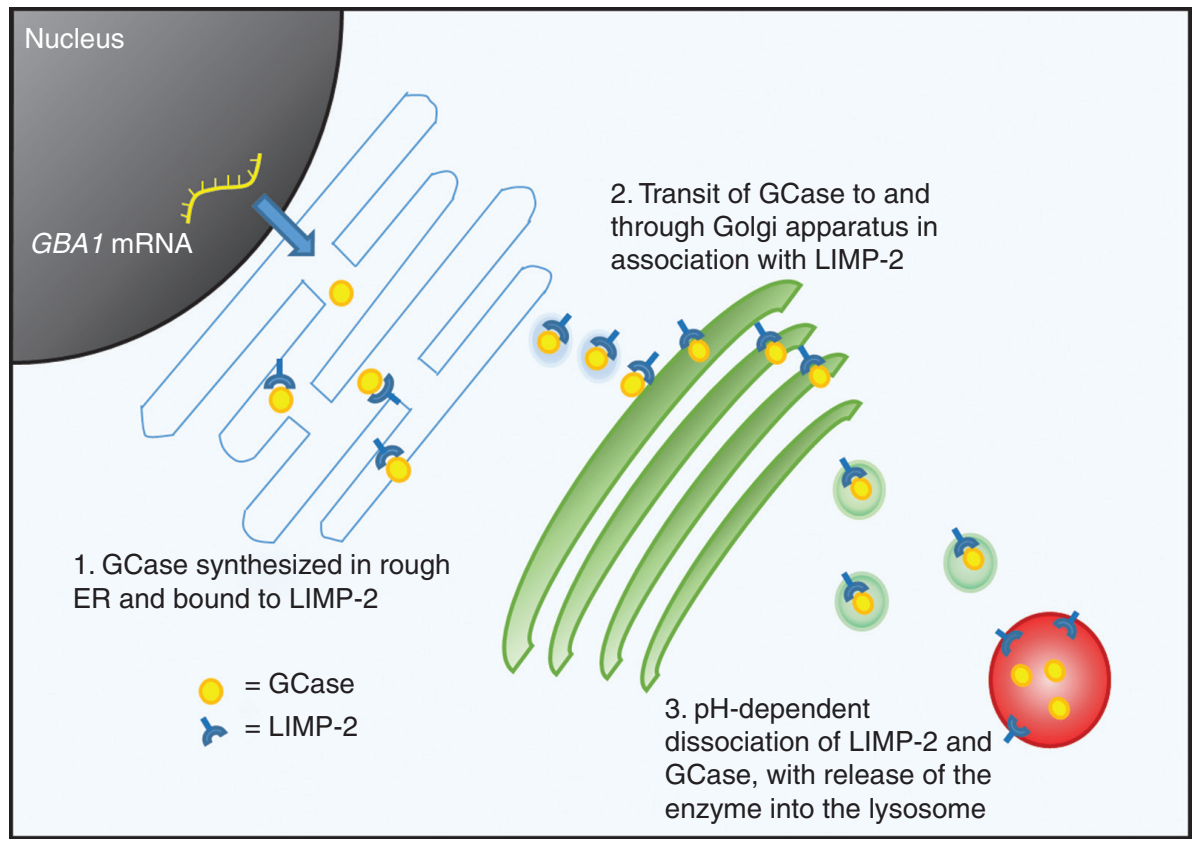

Figure 1 Synthesis and processing of GCase. GCase is synthesized in the rough ER where it becomes associated with LIMP-2. These two proteins transit in complex to the Golgi apparatus for processing. The GCase-LIMP-2 complex then migrates to the lysosome, where GCase is released into the lysosomal compartment, facilitated by $\mathrm{pH}$-dependent dissociation from LIMP-2. ER, endoplasmic reticulum; GCase, glucocerebrosidase; LIMP-2, lysosomal integral membrane protein-2; mRNA, messenger ribonucleic acid. 


\section{GBA1 MUTATIONS AND GAUCHER DISEASE}

Over 300 mutations in the GBA1 gene have been identified, which include point mutations, insertions, deletions, splice-site mutations, and recombinations $(14,15)$. Bi-allelic mutations result in negligible GCase enzyme activity and the autosomal recessive lysosomal storage disorder, Gaucher disease (GD), in which glucosylceramide accumulates in various organs and cells (particularly macrophages) (14). GD is classified based on the presence or absence of neurodegenerative features and the rate of clinical progression (16). Type 1 (non-neuronopathic) GD is characterized by hepatosplenomegaly, anemia and thrombocytopenia, and bone lesions. Types 2 and 3 (neuronopathic) GD are also associated with progressive neurological decline, which is rapid in type $3 \mathrm{GD}(6,14)$.

\section{ASSOCIATION BETWEEN GBA1 MUTATION AND PARKINSON'S DISEASE}

At the end of the 20th century, reports of an association between PD and GD began to emerge. A proportion of patients with type 1 GD were observed to develop a parkinsonian syndrome in adult life (17-19), and it was subsequently noted that first-degree relatives of GD patients (who were obligate or confirmed carriers of a single GBA1 mutation) also carried an increased risk of developing PD $(20,21)$. PD occurs in about $10 \%$ of patients with type 1 GD before the age of 80 years, compared to about $3-4 \%$ in the normal population (22).

A number of studies have since reported on the prevalence of GBA1 mutation in the PD population, with estimates ranging up to $21 \%$ (23). The prevalence of GBA1 mutations in PD is likely to have been overestimated in postmortem studies, in which cohorts may be more likely to include "atypical" or early-onset PD. It is generally accepted that about 5\% of PD patients carry a GBA1 mutation (24-28). In PD patients of Ashkenazi Jewish origin, the carrier frequency of GBA1 mutation is much higher at $15-20 \%(5,27)$. In contrast, $<1 \%$ of the general healthy population carries a mutation (3\% in the healthy Ashkenazi Jewish population) (27). This makes it numerically the most important known genetic risk factor for PD (6). Additionally, GBA1 mutations have been associated with dementia with Lewy bodies, providing further support that there is a pathogenic link between this gene and $\alpha$-synucleinopathies (29-31). It is, however, important to understand that GBA1 mutations do not cause a Mendelian form of PD, but are considered a genetic risk factor, increasing the risk $20-30$ fold $(6,15,27,32)$. In absolute terms, the penetrance of PD in association with this mutation is relatively low, with about $30 \%$ of carriers developing the disease before the age of 80 (6).

\section{PATHOGENIC MECHANISMS}

The hallmark of PD pathology is the presence of Lewy bodies and Lewy neurites which consist predominantly of $\alpha$-synuclein $(33,34)$. Abnormalities in a number 
of intracellular processes have now been implicated in GBA1 mutation-associated $\mathrm{PD}$, of which the one with greatest evidence base is dysfunction of the lysosome-autophagy system - a system known to be important in the clearance of $\alpha$-synuclein (35-38).

\section{Loss of function or gain of function?}

A growing number of studies have linked loss of GCase activity to PD pathology $(35,39-42)$. Some studies have found that loss of enzyme function results in accumulation of sphingolipid substrates, which potentially play a pathogenic role, as discussed below $(35,39,42)$. The loss-of-function hypothesis offers therapeutic targets for putative disease-modifying agents, which may act by augmenting GCase activity or removing substrates through other pathways.

GCase activity is reduced in several brain regions of individuals with sporadic and GBAl mutation-associated PD, and indeed in association with normal aging (43). Chemical suppression of GCase activity using conduritol- $\beta$ epoxide increases $\alpha$-synuclein levels in wild-type mice and in neuroblastoma cells $(39,40)$. Higher levels of $\alpha$-synuclein have also been observed in the olfactory bulb (44) and substantia nigra (40) in GD mice. Additionally, GBA1 knockout in wild-type mice results in aberrations in the lysosome-autophagy system and mitochondrial function, suggesting that loss of enzyme activity can negatively impact on other systems relevant to PD pathogenesis (45). Conversely, enhancing GCase activity can reduce $\alpha$-synuclein pathology in animal models $(46,47)$. While these studies have correlated reduced GCase activity with PD-relevant pathology, the mechanism by which this happens is yet to be clearly demonstrated. One possibility is that reduction in GCase activity results in accumulation of its sphingolipid substrates (42-44), which in turn stabilize the pathogenic species of $\alpha$-synuclein, contributing to its accumulation and aggregation $(35,48)$.

However, only a minority of GD patients, in whom GCase activity is negligible, develop PD (22). If the increased risk of PD in heterozygous GBAl mutation carriers relates to a loss of enzyme function, then one would expect a much higher incidence of PD within the GD population. Additionally, GBA1 mutations which do not significantly reduce enzyme activity have been associated with PD (49). It appears, therefore, that the pathogenic mechanisms of GBA1 mutation-associated $\mathrm{PD}$ are more complex than a simple reduction of enzyme activity and accumulation of substrates. Additionally, there are GBA1 mutations that do not cause GD, but that increase the risk of PD, further suggesting that the pathogenesis of GBA1 mutation-associated PD differs from that of GD (49).

The majority of pathogenic mutations in the GBAl gene are missense mutations that result in misfolding of the enzyme, and thus, an alternative hypothesis is that the pathogenicity of these mutations is conveyed by the gain of a toxic function of the misfolded enzyme. Misfolded GCase may be retained in the ER, leading to activation of the unfolded protein response (UPR) and ER-associated protein degradation (ERAD-see below). Prolonged activation of these systems and ongoing retention of misfolded enzyme may ultimately lead to activation of apoptotic pathways and neuronal loss. However, there are null mutations associated with PD risk, and as discussed above, knocking down GBA1 or inhibition of GCase activity in animal and cell models can recapitulate relevant $\alpha$-synuclein 
and PD pathology $(35,39-42)$. Gain of function therefore does not fully account for the increased risk of PD.

The mechanisms by which GBA1 mutations predispose to PD pathology are multifaceted, with several elements potentially being important. A further degree of complexity is added by the fact that different GBA1 mutations increase the risk of PD to different extents, and (at least in GD) there is a degree of genotype-phenotype correlation. For example, the common N370S mutation is rarely associated with neuronopathic GD, while homozygous L444P mutations result in type 3 GD, and some known mutations carry a much greater risk of PD development (e.g., L444P and $\mathrm{D} 409 \mathrm{H}$ ) than others (e.g., N370S) $(5,50)$. It is therefore conceivable that different pathogenic mechanisms are more or less pronounced in carriers of different mutations. The remainder of this section will outline what is currently known about the intracellular pathogenic mechanisms of GBA1 mutation-associated PD.

\section{Lysosome-autophagy dysfunction}

Autophagy is an umbrella term for some of the cell's major mechanisms of protein clearance and organelle turnover (51). Macroautophagy and chaperone-mediated autophagy are important in the degradation of $\alpha$-synuclein, and therefore, it is feasible that dysfunction of these systems can potentiate PD pathology. In chaperone-mediated autophagy, soluble proteins are directed to lysosomes by chaperone proteins for degradation by lysosomal enzymes $(52,53)$. In contrast, macroautophagy involves the formation of vacuolar structures called autophagosomes from cystosolic membrane fragments (phagophore). These autophagosomes take up proteins and other cellular waste before fusing with lysosomes to form an autolysosome. The contents are then degraded by the lysosomal compartment and recycled (Figure 2) $(51,53)$.

Dysfunction of the lysosome-autophagy system (in particular, macroautophagy) appears to be central to the pathogenic role of GBA1 mutations, with a growing number of studies reporting autophagy dysfunction in association with GBA1 mutation $(35,36,42,54)$. For example, increased numbers of lysosomes have been reported in neuroblastoma cells carrying GBA1 mutations (54) and inducedpluripotent stem cell (iPSC)-derived dopaminergic neurons from homozygous or heterozygous GBA1 mutation carriers $(36,42)$. Higher autophagosome numbers have also been reported in these studies $(42,54)$. Additionally, increased numbers of autophagosomes and lysosomes have been detected in neurons from wild-type mice treated with conduritol- $\beta$-epoxide, suggesting that these changes can occur due to reduced GCase enzyme activity (39).

While the lysosome-autophagy system is clearly implicated in PD associated with GBA1 mutations, the specific nature of the dysfunction is not understood. The possible sites of perturbation in macroautophagy could be at the level of:

i. biosynthesis of autophagosomes and/or lysosomes

ii. uptake of the targets of degradation into autophagosomes

iii. fusion of autophagosomes with lysosomes

iv. enzymatic degradation of the contents of the autolysosome (Figure 2).

The aforementioned observations of increased numbers of lysosomes and autophagosomes in in vitro and in vivo models of GBA1 mutation-associated disease 


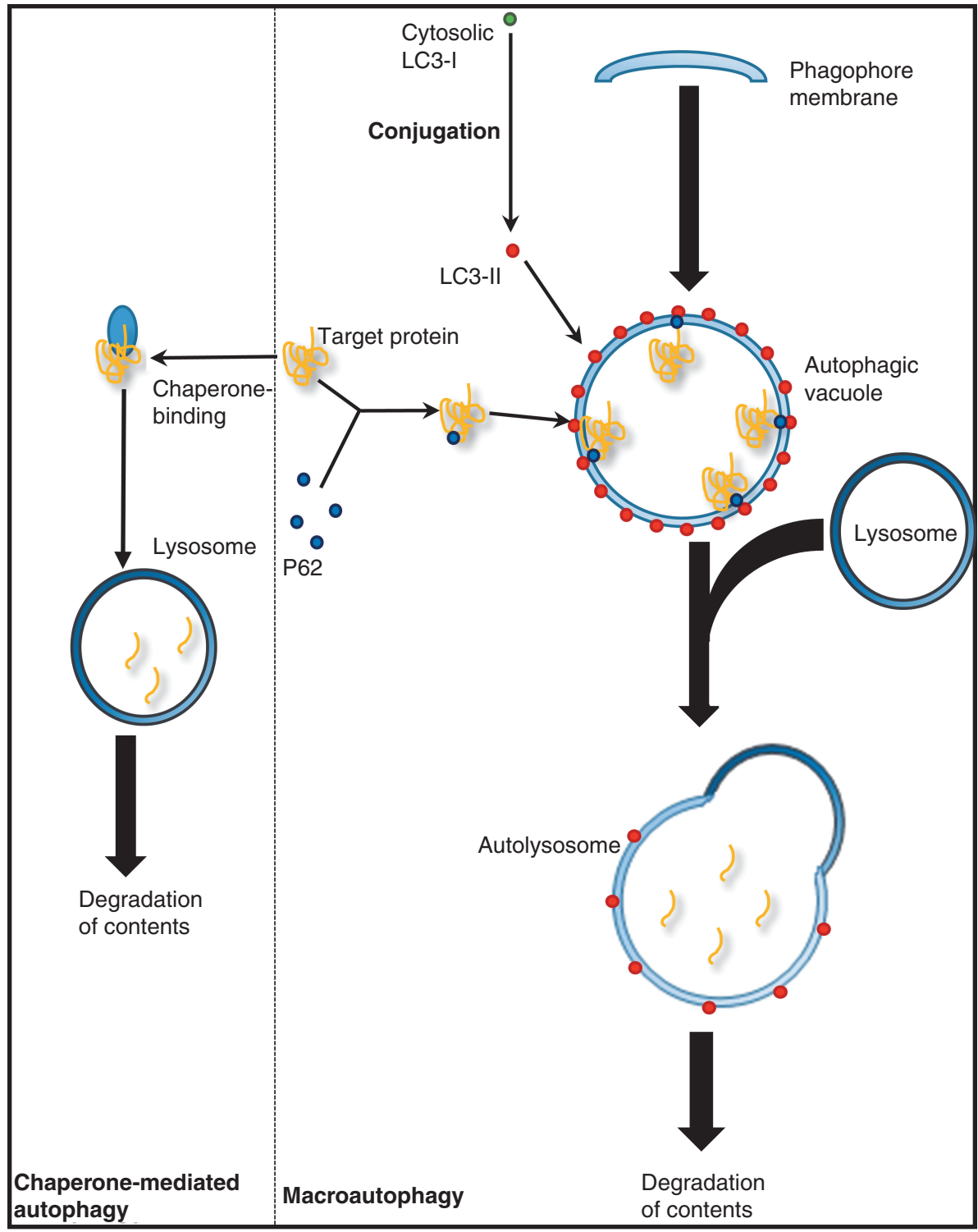

Figure 2 Macroautophagy and chaperone-mediated autophagy pathways. During macroautophagy, phagophore membrane fragments form autophagosomes. During this process, the protein LC-3 is conjugated. Proteins are targeted to the autophagosome, which involves the protein P62. The autophagosome fuses with the lysosome to form an autolysosome, and the contents are degraded by lysosomal enzymes. In chaperonemediated autophagy, proteins for removal bind to protein chaperones, which help to target them directly to the lysosome for enzymatic degradation. Together, these mechanisms constitute important pathways for $\alpha$-synuclein clearance. 
suggest that the site of dysfunction is not in the generation of these structures, but that it lies in the later stages of the pathway $(36,39,42,54)$. One possibility is that the increased number of these structures is due to increased activation of macroautophagy, perhaps as a compensatory response to other intracellular stresses. Alternatively, it could reflect an impairment in the fusion step of macroautophagy, which is supported by the observation that iPSC-derived neurons from GBA1 mutation carriers have reduced co-localization of autophagosomes and lysosomes compared to isogenic controls (42).

Other studies, however, suggest that the problem lies in the enzymatic function within the lysosome. Mazzulli and colleagues reported reduced lysosomal proteolysis in primary mouse cortical neurons with sh-RNA-mediated knockdown of GBA1 (35). Reduced lysosomal proteolysis may also be inferred by the observation that lysosomes in iPSC-derived dopaminergic neurons from GBAl mutation carriers are enlarged, with increased electron dense material, suggesting that their contents are not cleared appropriately (36). Therefore, while alterations in the function of the lysosome-autophagy system associated GBA1-mutation appear to occur, especially in the later stages of the macroautophagy pathway, the precise site of the dysfunction has yet to be conclusively shown.

Accepting that there is a problem with the lysosome-autophagy system in GBA1 mutation carriers, a question remains as to whether this is relevant to the increased risk of PD or whether it is an incidental observation associated with the mutation (taking into account the fact that only a minority of GD patients develop PD). $\alpha$-synuclein clearance is dependent on multiple pathways, but both macroautophagy and chaperone-mediated autophagy (both dependent on lysosomal hydrolysis) have been shown to be fundamentally important in its degradation $(38,55)$. In particular, a growing number of in vitro and in vivo studies have identified increased levels of $\alpha$-synuclein in association with lysosome-autophagy dysfunction in GBAl mutation or GCase suppression $(35,39-41,44,54,56-58)$. Therefore, for example, GBA1 knock-down in mouse cortical neurons has been shown to lead to reduced lysosomal proteolysis associated with reduced clearance of soluble and insoluble $\alpha$-synuclein (35). Lysosomal dysfunction has also been shown to increase exosomal release of $\alpha$-synuclein from the cell $(59,60)$, which may in turn then be taken up by adjacent neurons, resulting in aggregation of endogenous $\alpha$-synuclein in surrounding cells, all of which could account for the more accelerated clinical course seen in GBA-PD.

Taking into account the above discussion, it is clear that lysosome-autophagy system dysfunction in GBA1 is complex. A bidirectional loop has been proposed in which reduced GCase activity leads to perturbation in lysosomal function and accumulation of glycosphingolipid substrates, and accumulation of pathogenic oligomers of $\alpha$-synuclein (35). The GCase substrate glucosylceramide has been shown in vitro to lead to stabilization of pathogenic high molecular weight recombinant $\alpha$-synuclein oligomers, before accelerated aggregation $(35,48)$. The bidirectional loop is completed by the observation that $\alpha$-synuclein appears to impede transit and processing of GCase between the ER and the lysosome, resulting in a further reduction in lysosomal GCase activity (35). Further evidence for this comes from the observation that overexpression of $\alpha$-synuclein in cortical neurons results in an increase in the ER form of the enzyme and a reduction in the post-ER, glycosylated form of the enzyme (35), which fits with the 
finding of reduced GCase activity in some PD patients with wild-type GBA1 in some studies (39).

\section{Mitochondrial dysfunction and the role of oxidative stress}

Mitochondrial dysfunction is clearly important in PD pathogenesis, illustrated by the fact that mitochondrial toxins such as rotenone and 1-methyl-4-phenyl1,2,3,6-tetrahydropyridine (MPTP) induce death of dopaminergic neurons (61-63) and the fact that some hereditary forms of PD occur due to mutations in genes related to mitochondrial function and health (e.g., PINK-1 and DJ-1) (1). Few studies have commented on mitochondrial dysfunction in GBA1 mutationassociated disease, but there is some evidence that it plays a role $(41,45,57,64)$.

Suppression of GCase activity using conduritol- $\beta$-epoxide in neuroblastoma cells (41) and wild-type neurons in culture (57) results in a reduction in ATP production and oxygen consumption, demonstrating that mitochondrial dysfunction can occur as a result of reduced GCase enzyme activity. Additionally, a progressive reduction in mitochondrial membrane potential has been observed in vitro with prolonged GCase suppression, further supporting this idea (41). Furthermore, mitochondrial morphology and function are abnormal in GBA1 knockout mice, with the degree of abnormality greatest in homozygous compared to heterozygous knockout animals (45). In addition, reactive oxygen species are found in higher levels in the fibroblasts of PD patients carrying GBA1 mutations in comparison with those with wild-type GBA1 (65). These cells also had increased levels of the antioxidant, NQO1-a potential compensatory mechanism (65). Finally, protein aggregates including $\alpha$-synuclein have been noted to be localized to mitochondria in the hypomorphic prosaposin murine model of GD (57). While all these studies support a potential role for mitochondrial dysfunction in GBA1 mutation-associated PD, evidence is sparse in this area, and it is not clear whether these aberrations are directly related to abnormalities in GCase and the GBA1 gene, or alternatively are incidental markers of neurodegeneration.

It is possible that perturbations in mitochondrial function arise downstream of GBA1 mutation-induced $\alpha$-synuclein accumulation and aggregation. However, it has recently been suggested that oxidative stress is an earlier component of the pathogenic process in PD (66). Mitochondrial oxidant stress has recently been shown to be associated with DJ-1 knockout or dysfunction in dopaminergic neurons generated from patient-derived iPSCs, and after prolonged culture, this results in reduced GCase enzyme activity and impaired lysosomal proteolysis (66). While this process occurs in cells from patients with sporadic PD, it was accelerated in neurons derived from patients with homozygous DJ-1 mutations, suggesting that mitochondrial dysfunction is an important aspect of PD pathogenesis, potentially through inducing lysosomal dysfunction (66). Furthermore, mitochondrial antioxidants reduce the levels of soluble $\alpha$-synuclein, suggesting that oxidant stress contributes to $\alpha$-synuclein accumulation (66). This important study suggests that a sequential pathogenic pathway exists in $\mathrm{PD}$, in which mitochondrial oxidant stress leads to reduced GCase activity and lysosomal function, which potentially leads to $\alpha$-synuclein accumulation. GBA1 mutation may feed into this by lowering the threshold for, or altogether bypassing the need for, mitochondrial oxidant stress. 


\section{ER-stress}

As is discussed above, GCase is produced in the rough ER before it is processed in the Golgi apparatus and transported to the lysosome $(10,11)$. If proteins are not folded correctly in the ER, the misfolded protein may be retained for re-folding, mediated by ER chaperones $(67,68)$. Failure to correct the protein structure results in removal of the offending proteins via ERAD and the ubiquitin-proteasome system (67-69). GBA1 mutations, which result in structural change and misfolding of the protein, may result in activation of these systems $(70,71)$. Once their capacity to remove the misfolded protein is exceeded, activation of the UPR ensues $(36,72)$. If ER-stress is prolonged and the UPR fails to restore normal function, the cell may be directed to an apoptotic cell death fate. In support of this, increased levels of chaperone markers of ER-stress have been found in iPSC-derived neurons from PD patients carrying GBA1 mutations compared to controls, along with increased levels of markers of the UPR (36).

\section{Interaction with $\alpha$-synuclein}

An increasing number of studies have identified $\alpha$-synuclein accumulation in the setting of GBA1 mutation $(36,46,56)$. This may occur due to reduced clearance, secondary to dysfunction of the lysosome-autophagy system as discussed above $(35,36,66)$. However, GCase also appears to interact directly with $\alpha$-synuclein, and the significance of this is not known $(73,74)$. In one postmortem study, GCase was identified in 32-90\% of Lewy bodies of PD patients with GBA1 mutation, and in $10 \%$ of those with wild-type GBA1 (75). It is possible that this co-localization is a manifestation of the cell's attempt to clear these aggregates, but alternatively it may be that mutant GCase stabilizes $\alpha$-synuclein species or serves as a platform for fibrillization to occur. As well as these postmortem findings, recombinant GCase and $\alpha$-synuclein have also been shown to interact in vitro $(73,74)$. At lysosomal $\mathrm{pH}$, membrane-bound $\alpha$-synuclein forms a complex with GCase, resulting in reduced enzymatic function $(47,73,74)$. This interaction potentially explains the alterations in GCase activity that has been reported in PD with wild-type GBA1 $(50,76)$.

\section{CLINICAL ASPECTS OF GBA1 MUTATION-ASSOCIATED PD}

The characteristic motor features of PD include bradykinesia, rigidity, and resting tremor. Onset is usually asymmetric, and the disease progresses slowly over years. Other motor manifestations include postural instability, hypomimia, dysphonia, and altered posture. There are often additional non-motor features, such as anosmia, neuropsychiatric symptoms including depression and anxiety, sleep disturbance, autonomic dysfunction, and cognitive decline and dementia (1). At an individual level, PD patients carrying GBA1 mutations are clinically indistinguishable from those with sporadic PD. However, at a population level, GBA1 mutations are associated with differences in the age of onset, and incidence of cognitive involvement, in comparison with PD patients with wild-type GBA1 (24, 77-81). 
In this section, the clinical and imaging aspects of GBA1 mutation-associated PD will be discussed.

\section{Clinical features}

Age of onset is earlier in GBA1 mutation-associated PD, with multiple studies suggesting that motor manifestations occur between 2 and 10 years earlier than in sporadic PD patients (77-83). Additionally, GBA1 mutations are twice as common in those with PD of onset before age 50 than in later-onset cases $(81,82)$.

The clinical syndrome in PD associated with GBA1 mutations is similar to that seen in sporadic PD. However, motor progression to Hoehn and Yahr stage 3 (bilateral disease with development of postural instability) is accelerated in patients with GBA1 mutation, with an associated increase in mortality $(24,77,84)$. One study reported that GBA1 mutation carriers are more likely to present with tremor compared to patients with sporadic PD and that they have an increased risk of development of levodopa-induced dyskinesia (82). However, it should be noted that this group of patients were on significantly higher doses of levodopa compared to the sporadic PD patients which may explain the increased incidence of dyskinesia (82). Non-motor features, including REM-sleep behavior disorder, depression, anxiety, and hallucinations, are also said to be more prevalent in PD patients with GBA1 mutations compared to those without $(81,85-88)$. Depression and REM-sleep behavior disorder are also more common in individuals with heterozygous GBA1 mutations without a diagnosis of PD, compared to individuals with no mutation, which may reflect a prodromal phase of PD (85). Olfactory dysfunction is considered to be a prodromal non-motor feature of PD, and hyposmia has been identified at a greater incidence in individuals with heterozygous and homozygous GBA1 mutations compared to those with wild-type GBA1 $(85,86,89)$. The greater burden of non-motor symptoms in GBAl mutation carriers has been associated with lower quality-of-life scores compared to individuals with wild-type GBA1 (87). While autonomic features including constipation, bladder and erectile dysfunction, and orthostatic hypotension occur in GBA1 mutation-associated PD, they do not appear to be any more prevalent than in sporadic PD $(86,88,89)$.

The most significant difference in the clinical features of GBA1 mutationassociated PD compared to sporadic PD is the increased incidence and rate of cognitive decline $(24,77,84,86,88)$. The prevalence of dementia in individuals with sporadic PD who are over 65 years old is estimated to be between 24 and $31 \%(90)$. One retrospective longitudinal study found that $56 \%$ of GBA1 mutation carriers had dementia at age 70 , compared with $15 \%$ of sporadic PD patients (84). Carriers of GBA1 mutations had a threefold increased risk for dementia and approximately twofold increased risk of mortality, which was not entirely attributable to the dementia (84). This is consistent with findings from other studies $(77,86,88,91)$. Cognitive decline occurs more frequently in GBA1 mutation-associated $\mathrm{PD}$ compared to sporadic $\mathrm{PD}$, while the rate of progression is accelerated. In a community incident cohort of PD patients, those with GBA1 mutations had a median time to diagnosis of dementia of approximately four years, compared to eight years for those without GBA1 mutations (24). 


\section{Neuroimaging findings}

Imaging studies, using dopamine transporter imaging scans, magnetic resonance imaging (MRI) scans, transcranial sonography, and positron emission tomography (PET) scans, have all been used to look for differences between sporadic PD and PD associated with GBA1 mutation.

Dopamine transporter PET imaging (DaTSCAN) using the dopamine transporter ligands 18F-fluoropropylcarbomethoxyiodophenylnortropane (18F-FPCIT) and 123-ioflupane (123I-FP-CIT) have shown a greater degree of dopaminergic neuronal loss in PD associated with GBA1 mutation than in patients with wild-type GBA1 (84, 92-94). Asymmetry of radio ligand uptake is more pronounced in PD associated with GBA1 mutations than in some of the genetic forms of PD associated with a Mendelian inheritance pattern (SNCA, PINK1, or Parkin mutations) (92). However, a larger study in which F18-fluorodopa PET imaging was used to investigate patients with GBA1 mutation did not find any significant difference in dopamine synthesis, when compared with sporadic PD patients (95). Magnetic resonance diffusion tensor imaging (DTI) demonstrates reduced fractional anisotropy in a number of white matter tracts (corpus callous, anterior limb of internal capsule bilaterally, right anterior external capsule, and olfactory tracts) in PD patients with GBA1 mutations compared to those without mutations $(96,97)$. Although some subtle differences in the imaging features of GBA1 mutation-associated PD and sporadic PD have been described, the utility of these imaging techniques is largely limited to research at present. However, as refined treatments are developed, imaging findings may be useful in guiding genetic testing in PD, particularly when seeking mutations in the GBAl gene, as sequencing is complicated by the presence of a pseudogene in close proximity to the gene (as is discussed above).

\section{THERAPEUTIC PROSPECTS AND IMPLICATIONS}

Current treatment of GBA1 mutation-associated PD is the same as for sporadic PD. There are no specific treatments that modify the disease course in PD, with or without GBA1 mutation, and the current treatment involves the use of dopaminergic agents to improve motor symptoms. Understanding the mechanisms by which GBA1 mutations predispose to PD pathogenesis may offer novel therapeutic avenues and a greater prospect of identifying disease-modifying agents for this group of patients. Furthermore, given that some patients with sporadic PD also show a significant reduction in GCase activity (see above), it may also be that therapies targeting GCase dysfunction and its associated pathology are useful in other groups of PD patients as well (43).

As is discussed above, many studies suggest that reduced GCase enzyme activity is important in the pathogenesis of GBAl mutation-associated PD $(35,39-42)$. One approach, therefore, may be to augment enzyme activity, as is done in the treatment of non-neuronopathic GD (98). Enzyme replacement therapy and small molecule substrate reduction therapies are useful for the peripheral manifestations of GD, but do not cross the blood-brain barrier, therefore are unlikely to provide any meaningful improvement in the course of PD (99). 
A number of small molecule chaperones have recently been investigated for their ability to restore GCase function by binding to the misfolded enzyme that is retained in the ER and facilitating its correct re-folding, thus increasing lysosomal GCase levels and reducing ER stress. One of these compounds, isofagamine, yields an improvement in motor function, reduction in microglial activation, and a reduction in $\alpha$-synuclein aggregation in $\alpha$-synuclein over-expressing mice (100). This demonstrates that these compounds have the potential to alter central nervous system pathology. Another chaperone, ambroxol hydrochloride, is currently being investigated as a potential treatment for GBA1 mutationassociated PD. Ambroxol has been used as an expectorant since the 1980s and has been shown to increase lysosomal GCase levels and activity in several in vitro models $(65,71,101,102)$. Binding of ambroxol to GCase is pH-dependent, being strongest at the neutral $\mathrm{pH}$ of the ER, and allowing dissociation to occur in the acidic $\mathrm{pH}$ of the lysosome (103). Additionally, it seems that this increase in GCase activity enhances $\alpha$-synuclein clearance $(65,102)$. However, ambroxol does not appear to cross the blood-brain barrier, at least at the doses that are used clinically, and it remains to be seen whether this approach can be useful in GBA1 mutation-associated PD or GD (104).

As well as investigating GCase enhancement as a therapeutic option for GBA1 mutation-associated PD, it may be possible to slow disease progression by targeting the downstream mechanisms by which GBAl mutations increase PD risk, such as lysosome-autophagy system dysfunction. Rapamycin, an immunosuppressant agent, is a well-established inducer of macroautophagy (105), which has been shown to reduce $\alpha$-synuclein accumulation in a GBA1 mutation model in vitro (56). While rapamycin is unlikely to be used as a treatment for $\mathrm{PD}$ in view of its adverse effect profile, other drugs that are able to correct the lysosome-autophagy defect may be useful in GBAl mutation-associated PD. This may involve repurposing of drugs that are already established as treatments for other conditions, which are found to have a beneficial effect on autophagy. Potential examples of these agents include the tricyclic antidepressant nortriptyline, the disaccharide trehalose, and the antihypertensive rilmenidine (106-113).

Gene therapy, in which the GBA1 gene is introduced using a viral vector, has also been investigated in rodent models $(46,114)$. Memory impairment in a GD mouse model was reversed using this approach (114). However, given the widespread nature of pathology in GBA1 mutation-associated PD, reflected by the increased incidence and degree of cognitive impairment, it will be challenging to achieve effective delivery of the gene to the relevant population of cells, and much more work is required before this approach is considered suitable for the clinic.

\section{CONCLUSION}

As we enter the era of genomic sequencing, our understanding of genetic risk factors for conditions such as PD is becoming increasingly important. There are currently no disease-modifying therapies available for PD, and in view of the heterogeneous pathogenic mechanisms present in PD patients, it is likely that different treatment approaches will be necessary for different groups. 
Establishing the processes by which genetic susceptibility factors increase the risk of PD pathology provides the opportunity to develop specific therapies that target the relevant pathways in individual patients. GBA1 is now recognized as one of the most important genetic risk factors for PD, both numerically and clinically, with it leading to a greater degree of cognitive impairment and other non-motor features, all of which lead to a reduction in the quality of life in this population. Identification of drugs that are able to attenuate GBA1 mutationinduced pathology can therefore provide significant clinical benefit, and investigations toward this are under way.

Acknowledgment: The authors acknowledge the financial support from following organizations: Medical Research Council, Wellcome Trust Stem Cell Institute (Cambridge), NIHR Biomedical Research Centre, and Cure Parkinson's Trust.

Conflict of Interest: The authors declare no potential conflicts of interest with respect to research, authorship, and/or publication of this article.

Copyright and Permission Statement: To the best of our knowledge, the materials included in this chapter do not violate copyright laws. All original sources have been appropriately acknowledged and/or referenced. Where relevant, appropriate permissions have been obtained from the original copyright holder(s).

\section{REFERENCES}

1. Kalia LV, Lang AE. Parkinson's disease. Lancet. 2015;386(9996):896-912. http://dx.doi.org/10.1016/ S0140-6736(14)61393-3

2. Khoo TK, Yarnall AJ, Duncan GW, Coleman S, O'Brien JT, Brooks DJ, et al. The spectrum of nonmotor symptoms in early Parkinson disease. Neurology. 2013;80(3):276-81. http://dx.doi.org/10.1212/ WNL.0b013e31827deb74

3. Nalls MA, Pankratz N, Lill CM, Do CB, Hernandez DG, Saad M, et al. Large-scale meta-analysis of genome-wide association data identifies six new risk loci for Parkinson's disease. Nat Genet. 2014;46(9):989-93. http://dx.doi.org/10.1038/ng.3043

4. Williams-Gray CH, Goris A, Saiki M, Foltynie T, Compston DA, Sawcer SJ, et al. Apolipoprotein E genotype as a risk factor for susceptibility to and dementia in Parkinson's disease. J Neurol. 2009;256(3):493-8. http://dx.doi.org/10.1007/s00415-009-0119-8

5. Gan-Or Z, Giladi N, Rozovski U, Shifrin C, Rosner S, Gurevich T, et al. Genotype-phenotype correlations between GBA mutations and Parkinson disease risk and onset. Neurology. 2008;70(24): 2277-83. http://dx.doi.org/10.1212/01.wnl.0000304039.11891.29

6. Migdalska-Richards A, Schapira AH. The relationship between glucocerebrosidase mutations and Parkinson disease. J Neurochem. 2016 Oct;139 Suppl 1:77-90. http://dx.doi.org/10.1111/jnc.13385

7. Horowitz M, Wilder S, Horowitz Z, Reiner O, Gelbart T, Beutler E. The human glucocerebrosidase gene and pseudogene: Structure and evolution. Genomics. 1989;4(1):87-96. http://dx.doi. org/10.1016/0888-7543(89)90319-4

8. Beutler E. Gaucher disease: New molecular approaches to diagnosis and treatment. Science. 1992;256(5058):794-9. http://dx.doi.org/10.1126/science.1589760

9. Dvir H, Harel M, McCarthy AA, Toker L, Silman I, Futerman AH, et al. X-ray structure of human acid-beta-glucosidase, the defective enzyme in Gaucher disease. EMBO Rep. 2003;4(7):704-9. http:// dx.doi.org/10.1038/sj.embor.embor873

10. Jović M, Kean MJ, Szentpetery Z, Polevoy G, Gingras AC, Brill JA, et al. Two phosphatidylinositol 4-kinases control lysosomal delivery of the Gaucher disease enzyme, $\beta$-glucocerebrosidase. Mol Biol Cell. 2012;23(8):1533-45. http://dx.doi.org/10.1091/mbc.el1-06-0553 
11. Reczek D, Schwake M, Schröder J, Hughes H, Blanz J, Jin X, et al. LIMP-2 is a receptor for lysosomal mannose-6-phosphate-independent targeting of beta-glucocerebrosidase. Cell. 2007;131(4):770-83. http://dx.doi.org/10.1016/j.cell.2007.10.018

12. Ludwig T, Le Borgne R, Hoflack B. Roles for mannose-6-phosphate receptors in lysosomal enzyme sorting, IGF-II binding and clathrin-coat assembly. Trends Cell Biol. 1995;5(5):202-6. http://dx.doi. org/10.1016/S0962-8924(00)89000-5

13. O'Brien JS, Kishimoto Y. Saposin proteins: Structure, function, and role in human lysosomal storage disorders. FASEB J. 1991;5(3):301-8.

14. Hruska KS, LaMarca ME, Scott CR, Sidransky E. Gaucher disease: Mutation and polymorphism spectrum in the glucocerebrosidase gene (GBA). Hum Mutat. 2008;29(5):567-83. http://dx.doi. org/10.1096/fasebj.5.3.2001789

15. Lesage S, Anheim M, Condroyer C, Pollak P, Durif F, Dupuits C, et al. Large-scale screening of the Gaucher's disease-related glucocerebrosidase gene in Europeans with Parkinson's disease. Hum Mol Genet. 2011;20(1):202-10. http://dx.doi.org/10.1093/hmg/ddq454

16. Grabowski GA. Phenotype, diagnosis, and treatment of Gaucher's disease. Lancet. 2008;372(9645): 1263-71. http://dx.doi.org/10.1016/S0140-6736(08)61522-6

17. Neudorfer O, Giladi N, Elstein D, Abrahamov A, Turezkite T, Aghai E, et al. Occurrence of Parkinson's syndrome in type I Gaucher disease. QJM. 1996;89(9):691-4. http://dx.doi.org/10.1093/ qjmed/89.9.691

18. Sidransky E. Gaucher disease and parkinsonism. Mol Genet Metab. 2005;84(4):302-4. http://dx.doi. org/10.1016/j.ymgme.2004.11.007

19. Tayebi N, Walker J, Stubblefield B, Orvisky E, LaMarca ME, Wong K, et al. Gaucher disease with parkinsonian manifestations: Does glucocerebrosidase deficiency contribute to a vulnerability to parkinsonism? Mol Genet Metab. 2003;79(2):104-9. http://dx.doi.org/10.1016/S1096-7192(03)00071-4

20. Goker-Alpan O, Schiffmann R, LaMarca ME, Nussbaum RL, McInerney-Leo A, Sidransky E. Parkinsonism among Gaucher disease carriers. J Med Genet. 2004;41(12):937-40. http://dx.doi. org/10.1136/jmg.2004.024455

21. Halperin A, Elstein D, Zimran A. Increased incidence of Parkinson disease among relatives of patients with Gaucher disease. Blood Cells Mol Dis. 2006;36(3):426-8. http://dx.doi.org/10.1016/j. bcmd.2006.02.004

22. Rosenbloom B, Balwani M, Bronstein JM, Kolodny E, Sathe S, Gwosdow AR, et al. The incidence of Parkinsonism in patients with type 1 Gaucher disease: Data from the ICGG Gaucher Registry. Blood Cells Mol Dis. 2011;46(1):95-102. http://dx.doi.org/10.1016/j.bcmd.2010.10.006

23. Lwin A, Orvisky E, Goker-Alpan O, LaMarca ME, Sidransky E. Glucocerebrosidase mutations in subjects with parkinsonism. Mol Genet Metab. 2004;81(1):70-3. http://dx.doi.org/10.1016/j.ymgme.2003.11.004

24. Winder-Rhodes SE, Evans JR, Ban M, Mason SL, Williams-Gray CH, Foltynie T, et al. Glucocerebrosidase mutations influence the natural history of Parkinson's disease in a community-based incident cohort. Brain. 2013;136(Pt 2):392-9. http://dx.doi.org/10.1093/brain/aws318

25. Kumar KR, Ramirez A, Göbel A, Kresojević N, Svetel M, Lohmann K, et al. Glucocerebrosidase mutations in a Serbian Parkinson's disease population. Eur J Neurol. 2013;20(2):402-5. http://dx.doi. org/10.1111/j.1468-1331.2012.03817.x

26. Bras J, Paisan-Ruiz C, Guerreiro R, Ribeiro MH, Morgadinho A, Januario C, et al. Complete screening for glucocerebrosidase mutations in Parkinson disease patients from Portugal. Neurobiol Aging. 2009;30(9):1515-7. http://dx.doi.org/10.1016/j.neurobiolaging.2007.11.016

27. Sidransky E, Nalls MA, Aasly JO, Aharon-Peretz J, Annesi G, Barbosa ER, et al. Multicenter analysis of glucocerebrosidase mutations in Parkinson's disease. N Engl J Med. 2009;361(17):1651-61. http:// dx.doi.org/10.1056/NEJMoa0901281

28. Schapira AH. Glucocerebrosidase and Parkinson disease: Recent advances. Mol Cell Neurosci. 2015;66(Pt A):37-42.

29. Nalls MA, Duran R, Lopez G, Kurzawa-Akanbi M, McKeith IG, Chinnery PF, et al. A multicenter study of glucocerebrosidase mutations in dementia with Lewy bodies. JAMA Neurol. 2013;70(6):727-35. http://dx.doi.org/10.1001/jamaneurol.2013.1925

30. Goker-Alpan O, Giasson BI, Eblan MJ, Nguyen J, Hurtig HI, Lee VM, et al. Glucocerebrosidase mutations are an important risk factor for Lewy body disorders. Neurology. 2006;67(5):908-10. http:// dx.doi.org/10.1212/01.wnl.0000230215.41296.18 
31. Mata IF, Samii A, Schneer SH, Roberts JW, Griffith A, Leis BC, et al. Glucocerebrosidase gene mutations: A risk factor for Lewy body disorders. Arch Neurol. 2008;65(3):379-82. http://dx.doi. org/10.1001/archneurol.2007.68

32. Lesage S, Brice A. Parkinson's disease: From monogenic forms to genetic susceptibility factors. Hum Mol Genet. 2009;18(R1):R48-59. http://dx.doi.org/10.1093/hmg/ddp012

33. Spillantini MG, Schmidt ML, Lee VM, Trojanowski JQ, Jakes R, Goedert M. Alpha-synuclein in Lewy bodies. Nature. 1997;388(6645):839-40. http://dx.doi.org/10.1038/42166

34. Spillantini MG, Crowther RA, Jakes R, Hasegawa M, Goedert M. alpha-Synuclein in filamentous inclusions of Lewy bodies from Parkinson's disease and dementia with Lewy bodies. Proc Natl Acad Sci U S A. 1998;95(11):6469-73. http://dx.doi.org/10.1073/pnas.95.11.6469

35. Mazzulli JR, Xu YH, Sun Y, Knight AL, McLean PJ, Caldwell GA, et al. Gaucher disease glucocerebrosidase and $\alpha$-synuclein form a bidirectional pathogenic loop in synucleinopathies. Cell. 2011;146(1):37-52. http://dx.doi.org/10.1073/pnas.95.11.6469

36. Fernandes HJ, Hartfield EM, Christian HC, Emmanoulidou E, Zheng Y, Booth H, et al. ER stress and autophagic perturbations lead to elevated extracellular $\alpha$-Synuclein in GBA-N370S Parkinson's iPSC-Derived Dopamine Neurons. Stem Cell Reports. 2016;6(3):342-56. http://dx.doi.org/10.1016/j. stemcr.2016.01.013

37. Wong YC, Krainc D. Lysosomal trafficking defects link Parkinson's disease with Gaucher's disease. Mov Disord. 2016;31(11):1610-8. http://dx.doi.org/10.1002/mds.26802

38. Webb JL, Ravikumar B, Atkins J, Skepper JN, Rubinsztein DC. Alpha-Synuclein is degraded by both autophagy and the proteasome. J Biol Chem. 2003;278(27):25009-13. http://dx.doi.org/10.1074/jbc. M300227200

39. Rocha EM, Smith GA, Park E, Cao H, Graham AR, Brown E, et al. Sustained systemic glucocerebrosidase inhibition induces brain $\alpha$-Synuclein aggregation, microglia and complement $\mathrm{Clq}$ activation in Mice. Antioxid Redox Signal. 2015;23(6):550-64. http://dx.doi.org/10.1089/ars.2015.6307

40. Manning-Boğ AB, Schüle B, Langston JW. Alpha-synuclein-glucocerebrosidase interactions in pharmacological Gaucher models: A biological link between Gaucher disease and parkinsonism. Neurotoxicology. 2009;30(6):1127-32. http://dx.doi.org/10.1016/j.neuro.2009.06.009

41. Cleeter MW, Chau KY, Gluck C, Mehta A, Hughes DA, Duchen M, et al. Glucocerebrosidase inhibition causes mitochondrial dysfunction and free radical damage. Neurochem Int. 2013;62(1):1-7. http:// dx.doi.org/10.1016/j.neuint.2012.10.010

42. Schöndorf DC, Aureli M, McAllister FE, Hindley CJ, Mayer F, Schmid B, et al. iPSC-derived neurons from GBAl-associated Parkinson's disease patients show autophagic defects and impaired calcium homeostasis. Nat Commun. 2014;5:4028. http://dx.doi.org/10.1038/ncomms5028

43. Rocha EM, Smith GA, Park E, Cao H, Brown E, Hallett P, et al. Progressive decline of glucocerebrosidase in aging and Parkinson's disease. Ann Clin Transl Neurol. 2015;2(4):433-8. http://dx.doi. org/10.1002/acn3.177

44. Xu YH, Sun Y, Ran H, Quinn B, Witte D, Grabowski GA. Accumulation and distribution of $\alpha$-synuclein and ubiquitin in the CNS of Gaucher disease mouse models. Mol Genet Metab. 2011;102(4):436-47. http://dx.doi.org/10.1016/j.ymgme.2010.12.014

45. Osellame LD, Rahim AA, Hargreaves IP, Gegg ME, Richard-Londt A, Brandner S, et al. Mitochondria and quality control defects in a mouse model of Gaucher disease--links to Parkinson's disease. Cell Metab. 2013;17(6):941-53. http://dx.doi.org/10.1016/j.cmet.2013.04.014

46. Sardi SP, Clarke J, Viel C, Chan M, Tamsett TJ, Treleaven CM, et al. Augmenting CNS glucocerebrosidase activity as a therapeutic strategy for parkinsonism and other Gaucher-related synucleinopathies. Proc Natl Acad Sci U S A. 2013;110(9):3537-42. http://dx.doi.org/10.1073/pnas.1220464110

47. Barkhuizen M, Anderson DG, Grobler AF. Advances in GBA-associated Parkinson's disease--Pathology, presentation and therapies. Neurochem Int. 2016;93:6-25. http://dx.doi.org/10.1016/j.neuint.2015.12.004

48. Zunke F, Moise AC, Belur NR, Gelyana E, Stojkovska I, Dzaferbegovic H, et al. Reversible conformational conversion of $\alpha$-Synuclein into toxic assemblies by glucosylceramide. Neuron. 2018 Jan 3;97(1):92-107, e10.

49. Duran R, Mencacci NE, Angeli AV, Shoai M, Deas E, Houlden H, et al. The glucocerebrosidase E326K variant predisposes to Parkinson's disease, but does not cause Gaucher's disease. Mov Disord. 2013;28(2):232-6. http://dx.doi.org/10.1002/mds.25248 
50. Alcalay RN, Levy OA, Waters CC, Fahn S, Ford B, Kuo SH, et al. Glucocerebrosidase activity in Parkinson's disease with and without GBA mutations. Brain. 2015;138(Pt 9):2648-58. http://dx.doi. org/10.1093/brain/awv179

51. Klionsky DJ, Emr SD. Autophagy as a regulated pathway of cellular degradation. Science. 2000;290(5497):1717-21. http://dx.doi.org/10.1126/science.290.5497.1717

52. Cuervo AM, Dice JF. Lysosomes, a meeting point of proteins, chaperones, and proteases. J Mol Med (Berl). 1998;76(1):6-12. http://dx.doi.org/10.1007/s109-1998-8099-y

53. Dunn WA. Autophagy and related mechanisms of lysosome-mediated protein degradation. Trends Cell Biol. 1994;4(4):139-43. http://dx.doi.org/10.1016/0962-8924(94)90069-8

54. Bae EJ, Yang NY, Lee C, Lee HJ, Kim S, Sardi SP, et al. Loss of glucocerebrosidase 1 activity causes lysosomal dysfunction and $\alpha$-synuclein aggregation. Exp Mol Med. 2015;47:e153. http://dx.doi. org/10.1038/emm.2014.128

55. Cuervo AM, Stefanis L, Fredenburg R, Lansbury PT, Sulzer D. Impaired degradation of mutant alpha-synuclein by chaperone-mediated autophagy. Science. 2004;305(5688):1292-5. http://dx.doi. org/10.1126/science.1101738

56. Cullen V, Sardi SP, Ng J, Xu YH, Sun Y, Tomlinson JJ, et al. Acid $\beta$-glucosidase mutants linked to Gaucher disease, Parkinson disease, and Lewy body dementia alter $\alpha$-synuclein processing. Ann Neurol. 2011;69(6):940-53. http://dx.doi.org/10.1002/ana.22400

57. Xu YH, Xu K, Sun Y, Liou B, Quinn B, Li RH, et al. Multiple pathogenic proteins implicated in neuronopathic Gaucher disease mice. Hum Mol Genet. 2014;23(15):3943-57. http://dx.doi.org/10.1093/ hmg/ddul05

58. Fishbein I, Kuo YM, Giasson BI, Nussbaum RL. Augmentation of phenotype in a transgenic Parkinson mouse heterozygous for a Gaucher mutation. Brain. 2014;137(Pt 12):3235-47. http://dx.doi. org/10.1093/brain/awu291

59. Alvarez-Erviti L, Seow Y, Schapira AH, Gardiner C, Sargent IL, Wood MJ, et al. Lysosomal dysfunction increases exosome-mediated alpha-synuclein release and transmission. Neurobiol Dis. 2011;42(3):360-7. http://dx.doi.org/10.1016/j.nbd.2011.01.029

60. Bae EJ, Yang NY, Song M, Lee CS, Lee JS, Jung BC, et al. Glucocerebrosidase depletion enhances cell-to-cell transmission of $\alpha$-synuclein. Nat Commun. 2014;5:4755. http://dx.doi.org/10.1038/ ncomms 5755

61. Langston JW, Ballard P, Tetrud JW, Irwin I. Chronic Parkinsonism in humans due to a product of meperidine-analog synthesis. Science. 1983;219(4587):979-80. http://dx.doi.org/10.1126/ science. 6823561

62. Testa CM, Sherer TB, Greenamyre JT. Rotenone induces oxidative stress and dopaminergic neuron damage in organotypic substantia nigra cultures. Brain Res Mol Brain Res. 2005;134(1):109-18. http://dx.doi.org/10.1016/j.molbrainres.2004.11.007

63. Schapira AH. Mitochondria in the aetiology and pathogenesis of Parkinson's disease. Lancet Neurol. 2008;7(1):97-109. http://dx.doi.org/10.1016/S1474-4422(07)70327-7

64. de la Mata M, Cotán D, Oropesa-Ávila M, Garrido-Maraver J, Cordero MD, Villanueva Paz M, et al. Pharmacological chaperones and coenzyme Q10 treatment improves mutant $\beta$-Glucocerebrosidase activity and mitochondrial function in neuronopathic forms of gaucher disease. Sci Rep. 2015;5:10903. http://dx.doi.org/10.1038/srep10903

65. McNeill A, Magalhaes J, Shen C, Chau KY, Hughes D, Mehta A, et al. Ambroxol improves lysosomal biochemistry in glucocerebrosidase mutation-linked Parkinson disease cells. Brain. 2014;137(Pt 5):1481-95. http://dx.doi.org/10.1093/brain/awu020

66. Burbulla LF, Song P, Mazzulli JR, Zampese E, Wong YC, Jeon S, et al. Dopamine oxidation mediates mitochondrial and lysosomal dysfunction in Parkinson's disease. Science. 2017;357(6357):1255-61. http://dx.doi.org/10.1126/science.aam9080

67. Brodsky JL, McCracken AA. ER protein quality control and proteasome-mediated protein degradation. Semin Cell Dev Biol. 1999;10(5):507-13. http://dx.doi.org/10.1006/scdb.1999.0321

68. Sitia R, Braakman I. Quality control in the endoplasmic reticulum protein factory. Nature. 2003;426(6968):891-4. http://dx.doi.org/10.1038/nature02262

69. Yoshida H. ER stress and diseases. FEBS J. 2007;274(3):630-58. http://dx.doi.org/10.1111/j.17424658.2007.05639.x 
70. Ron I, Horowitz M. ER retention and degradation as the molecular basis underlying Gaucher disease heterogeneity. Hum Mol Genet. 2005;14(16):2387-98. http://dx.doi.org/10.1093/hmg/ddi240

71. Bendikov-Bar I, Maor G, Filocamo M, Horowitz M. Ambroxol as a pharmacological chaperone for mutant glucocerebrosidase. Blood Cells Mol Dis. 2013;50(2):141-5. http://dx.doi.org/10.1016/j. bcmd.2012.10.007

72. Høyer-Hansen M, Jäättelä M. Connecting endoplasmic reticulum stress to autophagy by unfolded protein response and calcium. Cell Death Differ. 2007;14(9):1576-82. http://dx.doi.org/10.1038/ sj.cdd. 4402200

73. Yap TL, Gruschus JM, Velayati A, Westbroek W, Goldin E, Moaven N, et al. Alpha-synuclein interacts with Glucocerebrosidase providing a molecular link between Parkinson and Gaucher diseases. J Biol Chem. 2011;286(32):28080-8. http://dx.doi.org/10.1074/jbc.M111.237859

74. Yap TL, Velayati A, Sidransky E, Lee JC. Membrane-bound $\alpha$-synuclein interacts with glucocerebrosidase and inhibits enzyme activity. Mol Genet Metab. 2013;108(1):56-64. http://dx.doi.org/10.1016/j. ymgme.2012.11.010

75. Goker-Alpan O, Stubblefield BK, Giasson BI, Sidransky E. Glucocerebrosidase is present in $\alpha$-synuclein inclusions in Lewy body disorders. Acta Neuropathol. 2010;120(5):641-9. http://dx.doi. org/10.1007/s00401-010-0741-7

76. Gegg ME, Burke D, Heales SJ, Cooper JM, Hardy J, Wood NW, et al. Glucocerebrosidase deficiency in substantia nigra of Parkinson disease brains. Ann Neurol. 2012;72(3):455-63. http://dx.doi. org/10.1002/ana.23614

77. Brockmann K, Srulijes K, Pflederer S, Hauser AK, Schulte C, Maetzler W, et al. GBA-associated Parkinson's disease: Reduced survival and more rapid progression in a prospective longitudinal study. Mov Disord. 2015;30(3):407-11. http://dx.doi.org/10.1002/mds.26071

78. Aharon-Peretz J, Rosenbaum H, Gershoni-Baruch R. Mutations in the glucocerebrosidase gene and Parkinson's disease in Ashkenazi Jews. N Engl J Med. 2004;351(19):1972-7. http://dx.doi. org/10.1056/NEJMoa033277

79. Tan EK, Tong J, Fook-Chong S, Yih Y, Wong MC, Pavanni R, et al. Glucocerebrosidase mutations and risk of Parkinson disease in Chinese patients. Arch Neurol. 2007;64(7):1056-8. http://dx.doi. org/10.1001/archneur.64.7.1056

80. Wu YR, Chen CM, Chao CY, Ro LS, Lyu RK, Chang KH, et al. Glucocerebrosidase gene mutation is a risk factor for early onset of Parkinson disease among Taiwanese. J Neurol Neurosurg Psychiatry. 2007;78(9):977-9. http://dx.doi.org/10.1136/jnnp.2006.105940

81. Neumann J, Bras J, Deas E, O'Sullivan SS, Parkkinen L, Lachmann RH, et al. Glucocerebrosidase mutations in clinical and pathologically proven Parkinson's disease. Brain. 2009;132(Pt 7):1783-94. http://dx.doi.org/10.1093/brain/awp044

82. Clark LN, Ross BM, Wang Y, Mejia-Santana H, Harris J, Louis ED, et al. Mutations in the glucocerebrosidase gene are associated with early-onset Parkinson disease. Neurology. 2007;69(12):1270-7. http://dx.doi.org/10.1212/01.wnl.0000276989.17578.02

83. Nichols WC, Pankratz N, Marek DK, Pauciulo MW, Elsaesser VE, Halter CA, et al. Mutations in GBA are associated with familial Parkinson disease susceptibility and age at onset. Neurology. 2009;72(4):310-6. http://dx.doi.org/10.1212/01.wnl.0000327823.81237.dl

84. Cilia R, Tunesi S, Marotta G, Cereda E, Siri C, Tesei S, et al. Survival and dementia in GBAassociated Parkinson's disease: The mutation matters. Ann Neurol. 2016;80(5):662-73. http://dx.doi. org/10.1002/ana.24777

85. Beavan M, McNeill A, Proukakis C, Hughes DA, Mehta A, Schapira AH. Evolution of prodromal clinical markers of Parkinson disease in a GBA mutation-positive cohort. JAMA Neurol. 2015;72(2):201-8. http://dx.doi.org/10.1001/jamaneurol.2014.2950

86. Goker-Alpan O, Lopez G, Vithayathil J, Davis J, Hallett M, Sidransky E. The spectrum of parkinsonian manifestations associated with glucocerebrosidase mutations. Arch Neurol. 2008;65(10):1353-7. http://dx.doi.org/10.1001/archneur.65.10.1353

87. McNeill A, Duran R, Hughes DA, Mehta A, Schapira AH. A clinical and family history study of Parkinson's disease in heterozygous glucocerebrosidase mutation carriers. J Neurol Neurosurg Psychiatry. 2012;83(8):853-4. http://dx.doi.org/10.1136/jnnp-2012-302402 
88. Wang C, Cai Y, Gu Z, Ma J, Zheng Z, Tang BS, et al. Clinical profiles of Parkinson's disease associated with common leucine-rich repeat kinase 2 and glucocerebrosidase genetic variants in Chinese individuals. Neurobiol Aging. 2014;35(3):725.el-6. http://dx.doi.org/10.1016/j.neurobiolaging.2013.08.012

89. McNeill A, Duran R, Proukakis C, Bras J, Hughes D, Mehta A, et al. Hyposmia and cognitive impairment in Gaucher disease patients and carriers. Mov Disord. 2012;27(4):526-32. http://dx.doi. org/10.1002/mds. 24945

90. Aarsland D, Zaccai J, Brayne C. A systematic review of prevalence studies of dementia in Parkinson's disease. Mov Disord. 2005;20(10):1255-63. http://dx.doi.org/10.1002/mds.20527

91. Setó-Salvia N, Pagonabarraga J, Houlden H, Pascual-Sedano B, Dols-Icardo O, Tucci A, et al. Glucocerebrosidase mutations confer a greater risk of dementia during Parkinson's disease course. Mov Disord. 2012;27(3):393-9. http://dx.doi.org/10.1002/mds.24045

92. McNeill A, Wu RM, Tzen KY, Aguiar PC, Arbelo JM, Barone P, et al. Dopaminergic neuronal imaging in genetic Parkinson's disease: Insights into pathogenesis. PLoS One. 2013;8(7):e69190. http://dx.doi. org/10.1371/journal.pone.0069190

93. Sunwoo MK, Kim SM, Lee S, Lee PH. Parkinsonism associated with glucocerebrosidase mutation. J Clin Neurol. 2011;7(2):99-101. http://dx.doi.org/10.3988/jcn.2011.7.2.99

94. Saunders-Pullman R, Hagenah J, Dhawan V, Stanley K, Pastores G, Sathe S, et al. Gaucher disease ascertained through a Parkinson's center: Imaging and clinical characterization. Mov Disord. 2010;25(10):1364-72. http://dx.doi.org/10.1002/mds.23046

95. Goker-Alpan O, Masdeu JC, Kohn PD, Ianni A, Lopez G, Groden C, et al. The neurobiology of glucocerebrosidase-associated parkinsonism: A positron emission tomography study of dopamine synthesis and regional cerebral blood flow. Brain. 2012;135(Pt 8):2440-8. http://dx.doi.org/10.1093/brain/aws174

96. Brockmann K, Hilker R, Pilatus U, Baudrexel S, Srulijes K, Magerkurth J, et al. GBA-associated PD. Neurodegeneration, altered membrane metabolism, and lack of energy failure. Neurology. 2012;79(3):213-20. http://dx.doi.org/10.1212/WNL.0b013e31825dd369

97. Agosta F, Kostic VS, Davidovic K, Kresojević N, Sarro L, Svetel M, et al. White matter abnormalities in Parkinson's disease patients with glucocerebrosidase gene mutations. Mov Disord. 2013;28(6):772-8. http://dx.doi.org/10.1002/mds.25397

98. Shemesh E, Deroma L, Bembi B, Deegan P, Hollak C, Weinreb NJ, et al. Enzyme replacement and substrate reduction therapy for Gaucher disease. Cochrane Database Syst Rev. 2015(3):CD010324. http://dx.doi.org/10.1002/14651858.CD010324.pub2

99. Lachmann RH. Enzyme replacement therapy for lysosomal storage diseases. Curr Opin Pediatr. 2011;23(6):588-93. http://dx.doi.org/10.1097/MOP.0b013e32834c20d9

100. Richter F, Fleming SM, Watson M, Lemesre V, Pellegrino L, Ranes B, et al. A GCase chaperone improves motor function in a mouse model of synucleinopathy. Neurotherapeutics. 2014;11(4):840-56. http:// dx.doi.org/10.1007/s13311-014-0294-x

101. Sanchez-Martinez A, Beavan M, Gegg ME, Chau KY, Whitworth AJ, Schapira AH. Parkinson diseaselinked GBA mutation effects reversed by molecular chaperones in human cell and fly models. Sci Rep. 2016;6:31380. http://dx.doi.org/10.1038/srep31380

102. Ambrosi G, Ghezzi C, Zangaglia R, Levandis G, Pacchetti C, Blandini F. Ambroxol-induced rescue of defective glucocerebrosidase is associated with increased LIMP-2 and saposin C levels in GBAl mutant Parkinson's disease cells. Neurobiol Dis. 2015;82:235-42. http://dx.doi.org/10.1016/j.nbd.2015.06.008

103. Maegawa GH, Tropak MB, Buttner JD, Rigat BA, Fuller M, Pandit D, et al. Identification and characterization of ambroxol as an enzyme enhancement agent for Gaucher disease. J Biol Chem. 2009;284(35):23502-16. http://dx.doi.org/10.1074/jbc.M109.012393

104. Weiser T. Ambroxol: A CNS drug? CNS Neurosci Ther. 2008;14(1):17-24. http://dx.doi. org/10.1111/j.1755-5949.2007.00032.x

105. Klionsky DJ, Abdelmohsen K, Abe A, Abedin MJ, Abeliovich H, Acevedo Arozena A, et al. Guidelines for the use and interpretation of assays for monitoring autophagy (3rd edition). Autophagy. 2016;12(1):1-222. http://dx.doi.org/10.1080/15548627.2015.1100356

106. Davies JE, Sarkar S, Rubinsztein DC. Trehalose reduces aggregate formation and delays pathology in a transgenic mouse model of oculopharyngeal muscular dystrophy. Hum Mol Genet. 2006;15(1): 23-31. http://dx.doi.org/10.1093/hmg/ddi422 
107. Gassen NC, Hartmann J, Zschocke J, Stepan J, Hafner K, Zellner A, et al. Association of FKBP51 with priming of autophagy pathways and mediation of antidepressant treatment response: Evidence in cells, mice, and humans. PLoS Med. 2014;11(11):e1001755. http://dx.doi.org/10.1371/journal. pmed.1001755

108. Sarkar S, Davies JE, Huang Z, Tunnacliffe A, Rubinsztein DC. Trehalose, a novel mTOR-independent autophagy enhancer, accelerates the clearance of mutant huntingtin and alpha-synuclein. J Biol Chem. 2007;282(8):5641-52. http://dx.doi.org/10.1074/jbc.M609532200

109. Lan DM, Liu FT, Zhao J, Chen Y, Wu JJ, Ding ZT, et al. Effect of trehalose on PC12 cells overexpressing wild-type or A53T mutant $\alpha$-synuclein. Neurochem Res. 2012;37(9):2025-32. http://dx.doi. org/10.1007/s11064-012-0823-0

110. Rodríguez-Navarro JA, Rodríguez L, Casarejos MJ, Solano RM, Gómez A, Perucho J, et al. Trehalose ameliorates dopaminergic and tau pathology in parkin deleted/tau overexpressing mice through autophagy activation. Neurobiol Dis. 2010;39(3):423-38. http://dx.doi.org/10.1016/j. nbd.2010.05.014

111. Zschocke J, Rein T. Antidepressants encounter autophagy in neural cells. Autophagy. 2011;7(10): 1247-8. http://dx.doi.org/10.4161/auto.7.10.16520

112. Rubinsztein DC, Codogno P, Levine B. Autophagy modulation as a potential therapeutic target for diverse diseases. Nat Rev Drug Discov. 2012;11(9):709-30. http://dx.doi.org/10.1038/nrd3802

113. Underwood BR, Green-Thompson ZW, Pugh PJ, Lazic SE, Mason SL, Griffin J, et al. An open-label study to assess the feasibility and tolerability of rilmenidine for the treatment of Huntington's disease. J Neurol. 2017;264(12):2457-63. http://dx.doi.org/10.1007/s00415-017-8647-0

114. Sardi SP, Clarke J, Kinnecom C, Tamsett TJ, Li L, Stanek LM, et al. CNS expression of glucocerebrosidase corrects alpha-synuclein pathology and memory in a mouse model of Gaucher-related synucleinopathy. Proc Natl Acad Sci U S A. 2011;108(29):12101-6. http://dx.doi.org/10.1073/ pnas. 1108197108 